\title{
Public Sector Software, Participatory Communications and Social Change
}

\author{
Pradip Ninan Thomas ${ }^{1}$
}

\begin{abstract}
This article explores the role played by public sector software (PSS) in social change in India. Viewing public sector software as a public good, it explores its potential as well as the challenges that it faces in a context in which proprietoral software is an established and dominant force. Using both theory and examples, it argues that state investment in this public good makes infinite sense in the context of e-governance and commitments to access and affordable use of information resources for all its citizens. Based on the principles of Free Open Source Software (FOSS), PSS offers not only possibilities of access but also adaptation and use by a variety of 'recursive publics'. Using the example of PSS in the Southern Indian state of Kerala, it offers insights into the practical benefits of software deployed for the common good.
\end{abstract}

Keywords: Public Sector Software, FOSS, public good, risk society, access, social change

\section{Introduction}

While the state in India has played an ambivalent role in development, there have been occasions when it has taken a lead in investing in people-centred change processes. Such occasions are all too rare and, more often than not, the impetus for them stems from lobby efforts undertaken by civil and political society.

V.S. Naipaul has characterised India as the 'land of a million mutinies'. Social movements such as the grassroots Right to Information movement and the very middle-class anti-corruption struggle related to the Lokpal Bill (aimed at creating a supra-national anti-corruption authority based on substantive inputs from civil society) suggest that the Indian polity are clearly unhappy with the state of politics, irrespective of where they are situated on the class/caste hierarchy. In particular, they are unhappy with the myriad 'scams' and the institutionalisation of 'graft'.

One investment in broadly people-centred development is current joint civil societystate initiatives to explore a practical basis for investments in, and deployments of, public sector software (PSS). Given the government's extensive investments in development, it makes sense, in a knowledge economy, to invest also in cost-effective, non-proprietary, inter-operable public software that can be accessed and used by citizens in their own development. In light of the critical role played by information flows in the context of 
any government, there is a need to invest in e-government services and maximise citizen's access to, and use of, this information for social and economic ends.

The moves to explore the possibilities for public sector software in India were precipitated by several factors. First, the realisation of the breadth and depth of public sector investments in the digital revolution inclusive of the informationalisation of services and infrastructure development. Second, the recognition of the critical roles played by information and knowledge in society and the economy. Third, the evidence of vendor lock-in, particularly the overwhelming presence of Microsoft as the single, dominant software player in the public sector and the financial costs associated with licensing along with the political economy of intellectual property (IP). Fourth, a recognition of the strengths, particularly access to software code, interoperability, and costs associated with Free and Open Source Software (FOSS). Fifth, the billions of dollars worth of investments in e-governance and issues related to software deployment and access to information. And sixth, broader public domain issues articulated by champions of open access both within and outside of the public sector in different parts of the world.

\section{The Public Sector in India}

PSS needs to be viewed in the context of India's commitment to public sector-based investments related to development. Given the scale of issues that faced the Indian nation at its independence - poverty, unemployment and lack of development, planned development was seen as an answer. This led to the institution of the Planning Commission in 1950 and growth based on successive Five Year Plans. Through its public works, the Indian State subsidies lives and livelihoods for the majority of Indians - literally millions of people. Employment in the public sector in 1981 was in the region of 15.5 million, "68 per cent of the total employment in the organised public and private sectors" (Indian Labour Market Report 2008). While economic liberalisation in the 1990s has led to disinvestments in the public sector, public sector expenditures continue to grow. Public sector projects such as the National Rural Employment Guarantee Scheme (NREGA), that guarantees 100 days of employment for the rural poor in public works projects, and the Public Distribution System, that facilitates the purchase of subsidised grains and oils, enable vast sections of the Indian population to stay alive. In this sense, the public sector is involved in creating equity, justice and a level playing field in a variety of sectors including education, health, agriculture, manufacturing and industry. However, as well known, it is also plagued with corruption, lack of accountability and politicisation - issues that have been exposed through movements such as the Right to Information (see Thomas 2011).

Although the Indian state is often described as a liberal democracy, if one were to assess the relationship between its political economy and the exercise of power it would become immediately apparent that the country has a long way to go in terms of ensuring equity and justice for all. In this light, the Indian state could rather be described as 'competitive authoritarian', albeit with substantial freedoms and options for civil society. If described as such, the public sector can be viewed as a space in which the allocation of public goods and services has been finely tuned through multiple exercises of 'graft'. In turn, PSS can be seen as an opportunity for the government to move on 
from being top-down, over-bureaucratised and corrupt to being transparent, accountable and people-centred.

PSS's objectives are explicitly linked to furthering universal access, participation and affordable use of software by the majority of people in India. Notwithstanding issues related to increased possibilities for the state to extend its surveillance capacities via e-governance, the positive freedoms associated with PSS should not be discounted; namely, the potential to unleash creativity and innovation through collaborative learnings, applications and co-creation. In the context of the right to information, PSS can also be leveraged by ordinary people to reform governance and make the public sector accountable to its publics.

The space and opportunities for public sector software are best illustrated by current investments in e-governance, such as the US\$4.46 billion investment by the Government of India in the National e-Governance Plan (see Kanungo 2010), pre-existing research and development initiatives related to FOSS, and policy initiatives like the Ministry of Information and Communication Technology's draft policy on Open Standards for e-Governance (2009). To some extent, PSS as an aspect of the new approach to public management in India is an outcome of internal reform as well as external pressure -such as public sector adoption of the right to information and adoption of 'transparency' as a key principle of governance. This new approach is based on increased efficiency, decentralisation, increased accountability, improved resource management and marketisation (Heeks 1998).

\section{Defining Public Sector Software}

While PSS shares a number of characteristics of FOSS including the freedom to modify and share software, "Public Software... is organised on public goods principles, that certain goods whose production may not offer sufficient incentives for the private sector and whose availability is important to all in society, need to have an alternate model of production and distribution. Public Software thus emphasises the 'positive right' of citizens - that basic software for negotiating digital society is their entitlement. It concerns the public sector and its role and obligations to society".

PSS is an increasingly important issue for governments throughout the world, such as e.g. those of the UK, Germany, France, the Netherlands, Denmark, South Africa and Brazil, which have increased investments in e-governance, leading to complementary efforts to explore cost-effective software solutions, the most efficient inter-operability standards, and ways to strengthen 'universal and affordable access'. In the UK there are moves to speed up the adoption of open source software on public sector IT systems, thus saving on licensing fees and avoiding proprietary software lock-ins (see Allen 2009: 8). There is a belief that open source software and open standards can ensure greater transparency, independence and flexibility leading to sustainable, long-term solutions. This intent to invest in PSS is however part of a change in the mentality of government hitherto limited to investments in the collection of information from its citizens through exercises such as the census for the purposes of governmentality to making available vast collections of data-sets for public use. The re-use of public sector information, beginning with the Directive 2003/98/EC of the European Parliament and the Council of 17 November 2003 on the re-use of public sector information, makes a case for an 
internal market for public sector information. As the directive points out "The public sector collects, produces, reproduces and disseminates a wide range of information in many areas of activity, such as social, economic, geographical, weather, tourist, business, patent and educational information... Public sector information is an important primary material for digital content products and services". In the UK, between " 15 and $25 \%$ of information products and services are based on information produced or held by the public sector" and the re-use of that information has become an important aspect of that government's transparency agenda.

In 2009, Tim Berners-Lee, often described as the father of the world wide web, was invited by the then prime minister of Britain Gordon Brown, to explore possibilities to unlock and make publicly available literally hundreds of public datasets for public use. As Chatfield \& Crabtree (2010: 44-45) describe it, Whitehall civil servants were exposed to the cultural politics and convictions of an open source enthusiast: "Most Whitehall computers run on a heavily encrypted network called the 'government secure intranet'. But Berners-Lee, used to his own laptop, demanded wireless internet access. He also wanted his team to use an open source project management tool, called Basecamp. The biggest bone of contention, however, came over Microsoft Word. Much government work is done by civil servants emailing Word documents back and forth. Yet BernersLee refuses, on principle, to use Word, which is a proprietary rather than an open source format. On one occasion, one official recalled, Berners-Lee received an urgent document in Word from one of the most senior civil servants - and refused to look at it until a junior official had rushed to translate it into an acceptable format". This example is illustrative of a gradual change in government circles towards an acknowledgement of the value of collaborating with representatives from civil society.

In India, organisations like the Bangalore-based IT for Change and the Centre for Internet and Society are regularly consulted by the government on matters such as PSS and internet regulation.

\section{Proprietorial Software \& Open Standards}

What seems to be the trend in most of the world is not the complete marginalisation of proprietary software but an openness to the need for mixed systems in e-governance. In the case of India, the networking of public libraries using the e-Granthalaya software developed by the National Informatics Centre is based on Microsoft technology and "runs on a Windows platform in client/server mode over a local area network or on stand-alone system...Version 3 is being developed in collaboration with the Microsoft Corporation as a development partner...The e-Granthalaya software is being distributed free of charge to all Government libraries, including public libraries in India, under NIC's e-Governance support role" (Matoria, Upadhyay \& Moni 2007: 52).

While a mixed approach is favoured by a number of governments, there is also an increased wariness of e-governance solutions based on proprietorial software, given the virtual monopoly that vendors such as Microsoft continue to exert throughout the world. A number of governments have experienced 'lock-ins' that are a result of the deployments of proprietorial software in e-governance projects and there is a growing consensus that software used to generate, manage and process 'public' data needs to be publicly owned and operated. Ghosh et.al. (2008: 23) make the point that a "proprie- 
tory system for web server administration" used by government services "can result in a requirement that all future additions to the web site... be made with the same proprietary system". This can force all stakeholders involved in maintaining and using this site to continue using the products of a single vendor. Furthermore, if any given vendor controls software standards, this can result in a lack of compatibility between existing hardware, operating systems and file formats deployed in e-governance, e-administration and e-government initiatives.

Inter-operability, which remains an issue within national territories, can be an even more complex issue in the context of supra-national states such as the European Union, where member states use different standards, leading to higher transactional costs and inefficiencies in information flows.

In an article on 'metadata interoperability in public sector information', Bountouri et. al. (2009: 205) highlight the various levels that can be affected and that are a consequence of differing standards/protocols and heterogeneity in software applications:

- "syntax - heterogeneities caused by the differences between protocols, encodings and languages used by information sources (i.e. query languages, data formats etc.);

- schema - heterogeneities coming from the implementation of different data models, data structures and schemas;

- semantic - heterogeneities produced by semantic conflicts arising from the fact that the meaning of the data can be expressed in different ways and with different interpretations; and

- system - heterogeneities arising from different hardware platforms, operating systems and networking protocols".

These concerns are being addressed in India, although the extent of progress made at each level is unclear. The National Informatics Centre is involved in exploring standards for e-governance, and 'metadata and data standards for application domains' is one of several areas that they are currently working on, including network and information security, quality and documentation, localisation and language technology standards and technical standards and e-governance architectures.

\section{Theorising Public Sector Software}

\section{Public Sector Software as a Public Good}

One of the ways to theorise public sector software is to explore it as a public good. Since a key quality of the digital is its 'non-rivalrous' nature, it can become the basis for a non-excludable approach to the provision of an essential good - software, and services associated with it. There are no additional costs related to the consumption of public sector software.

While public goods can certainly be delivered by the private sector and civil society, in partnership with the public sector or independently, in the context of a country like India, characterised by high poverty rates and divides, the state plays a preeminent role in the lives of its citizens. However, this role is an extraordinarily ambivalent one. While on the one hand the state's machinery of law and order has been used to 
suppress dissent and is therefore viewed as a key enemy by vast sections of the Indian population (especially in the Maoist controlled Eastern belt and in North East India), on the other hand it plays a significantly progressive role in society and supports public interests.

In this sense, the Indian state has to be theorised as a multi-faceted and multi-layered entity shaped by regressive nationalistic urges while also being involved in the shaping of progressive people-centred initiatives and spaces supportive of the argumentative Indian. It continues to play a dominant role even in the context of the privatisation of large parts of the Indian economy and economic liberalisation precisely because it is involved in subsiding large sections of the Indian population whose links with economic globalisation are tenuous at best. These people are beyond the pale of development and the reach of 'civil society'. As the post-colonial scholar and political scientist Partha Chatterjee (2004: 38-39) has observed, "Most of the inhabitants of India are only tenuously, and even then ambiguously and contextually, rights-bearing citizens in the sense imagined by the constitution... Civil society as an ideal continues to energise an interventionist political project, but as an actually existing form it is demographically limited".

Chatterjee has argued that in the context of India it is 'political society', rather than 'civil society', that has the greatest influence on people. He uses the term 'political society' to refer to communities such as urban squatters, who live lives that are only tangentially linked to the state and civil society but who organise themselves 'politically' to negotiate entitlements with the state. While such distinct characterisations of civil society and political society can be critiqued, it is certainly true that the millions of people who often exist beyond the pale of development really have not had any truck with civil society or experienced popular sovereignty, freedom and equality. These populations have had problematic experiences with formal citizenship and lead lives largely unconnected with the practices of NGOs and associations involved in advancing public interests. They are however part of political society, given that they mobilise themselves politically and use their strength as a vote bank to negotiate entitlements with the state. "What happens then is a negotiation of these claims on a political terrain where, on the one hand, governmental agencies have a public obligation to look after the poor and the underprivileged and, on the other, particular population groups received attention from those agencies according to calculations of political expediency" (40). When dealing with public sector goods and services, it is also important to make the point that the free market by its very nature is exclusionary. In that sense, the private sector cannot be expected to deliver on 'universal services', best illustrated by shortfalls in their obligations - e.g. in the area of the provision of telecommunications in both the developed and the developing world. In the case of Australia, perceived shortfalls in the provision of universal service obligations by the dominant vendor Telstra have led to the federal government investing $\mathrm{A} \$ 36$ billion in broadbanding the country via the National Broadband Corporation. In India too, the government-based incumbent local fixed line provider, the Bharat Sanchar Nigam Limited (BSNL), is, by far, the single largest contributor to universal service obligations. Private sector companies have opted to pay fines rather than fulfil their universal service obligations. 


\section{Recursive Publics and Actor Network Theory (ANT)}

What is significant about public software is that it is a public good with a difference. While efficiency, inter-operability and inter-sectoral networking and flows are key objectives, there is also a commitment to opening up public information to the public via software that can be freely adapted by individuals and communities of interest. Christopher Kelty $(2008,2005)$ has used the term 'recursive publics' to describe individuals and communities of interest who have the skills and knowledge to manipulate source codes and create software programs of choice. While not all people have the capacity to manipulate software, public sector software certainly provides opportunities to those who have such capacities. Software programming is typically made through recursive practices - meaning repetitive processes that result in the ironing out of dead ends. Today, the FOSS community not only consists of programmers but also of those who have intimate knowledge of the various layers - the technology, the legal layer and protocols - and who use this knowledge to construct a social imaginary for software use that is different from mainstream understandings. Kelty (2008: 10-11) has argued that such recursive publics are involved in a reorientation of power and knowledge through their capacities to build, modify, subvert, control, adapt ideas, processes and infrastructures: "Availability is a broad, diffuse and familiar issue. It includes things like transparency, open governance or transparent organisation, secrecy and freedom of information, and open access in science... Modifiability includes the ability to not only access -that is, to reuse in the trivial sense of using something without restrictions- but to transform it for use in new contexts, to different ends, or in order to participate directly in its improvement and to redistribute or recirculate those improvements within the same infrastructures while securing the same rights for everyone else".

One can argue that these recursive publics and the networks they create can be assessed via the analytical lens provided by actor network theory (ANT). In contrast to the diffusion model in which technologies are seen as fixed and immutable, actor network theory takes into account the relationship between social actors and technologies, and the mutual social shaping that results from this relationship. Both people and technologies can act and can be acted upon (Holmstrom \& Robey 2005).

ANT recognises that networks consist of the social, the organisational and the technological working together, that these are dynamic processes, and that the 'interactivity' and the 'relationality' generate 'actions' within networks. Actor networks are by their very nature contingent, flexible and the result of shifting influences of stable and unstable elements in any given environment.

\section{The Role of Public Sector Software in the Risk Society}

The issue of dependency that was discussed in the context of media imperialism and the New World Information and Communication Order (NWICO) was, in my way of thinking, rather hastily marginalised in the wake of perceived, multi-way, transnational information and communication flows. It is clear that, via aid and technology transfers, dependencies of one type or the other continue to shape development in many parts of the world. Dependency in the context of e-governance does have major security implications given that any vendor's control over public data sets can compromise a nation's sovereignty. Dependency has been a characteristic feature of global software given the 
monopoly that vendors such as Microsoft have enjoyed for close to three decades.

The issue of informational dependency in the context of the $21^{\text {st }}$ century, however, is qualitatively different from media dependency in the $20^{\text {th }}$ century. In the context of convergent, informational capitalism, characterised by the informationalisation of all productive and life processes, dependency can have serious consequences for any government. Federspeil and Brincker (2010) employ the German political theorist Ulrich Beck's notion of the risk society to understand current anxieties related to software standards in Denmark. On January 1, 2008, the country passed a resolution that supported open standards for all public sector software. As Federspeil and Brincker point out, "bearing in mind Beck's definition of risk, software lends itself to risk analysis: The software market transcends national states - in fact, national states are apparently quite unable to regulate or control this market. The software market produces and delivers products on which the public sectors are completely dependent. This is particularly evident in countries like Denmark where the public sector has undergone digitalisation. Finally, one cannot insure against data losses, malfunctioning electronic filing systems, or breakdowns in communication infrastructures, the consequences of which are difficult to quantify and thereby compensate in monetary terms. Therefore, the risks associated with software may be characterised as incalculable" (ibid: 41). Beck's understanding of 'risk' is based on the various environmental hazards facing the globe in the context of late modernity and, in a situation characterised by the globalisation of risk best illustrated by catastrophes such as Chernobyl and Fukushima, the relative powerlessness of the state to deal with the intended and unintended consequences and risks associated with progress and growth. Beck (1999) describes global factors including the rise of network societies, and its consequences for nation states that have had to re-calibrate their security systems: "The world society created by globalisation cuts across national state boundaries, not only economically, but through a multiplicity of social circles, communication networks, market relations and lifestyles, none of them specific to any locality" (ibid: 25).

The network society's harmonisation of data flows -economic, political, cultural, and social- has certainly contributed to the strengthening of faith in the ability of global capitalism to contribute to growth and progress. However, this hope and certainty are offset by issues related to the security of data flows and the inability to control these flows given the 'uncontrollable' nature of the digital. In an article on Ulrich Beck's writings, Cottle (1998: 8) has observed: "The nature of contemporary 'risks' for Beck are historically unprecedented in terms of their spatial and temporal reach, their potential catastrophic effects and, importantly, their invisibility". While there is no denying the tremendous contributions to growth in India by the services sectors, how to manage this growth without endangering the security and sovereignty of the nation is an issue that is of concern to the Indian government. e-Governance has already begun to generate vast amounts of data on the public, and public sector software is a way of ensuring that this data is managed primarily in support of the national interest. While the draft National Policy on Open Standards in e-Governance (2009) does acknowledge security concerns in clause 4.7, its specific objectives support the national interest. These include the promotion of innovation and entrepreneurship in e-Governance, the availability of e-governance services in numerous Indian languages, cost effective access, and interoperable e-Governance systems. 
One can argue that public sector software mitigates the risk of "organised irresponsibility". Here Beck's suggestion for the need for 'relations of definition' (1997: 29) is useful again, because it refers to the role played by 'rules, institutions and resources' in the mitigation of such risks.

Four questions can be applied to understanding risk in terms of not only e-governance but also all 'development' projects supported by the state and the private sector in the context of contemporary India:

“1) Who -that is, what social agency and authority establishes in what way how harmless or dangerous products and their side-effects are? Does the responsibility lie with those who create and profit from the risks, or with those who are currently or potentially affected, or with public agencies?

2) What type of knowledge or unawareness of causes, dimensions, agents and so on is consulted or acknowledged here? Who bears the burden of proof?

3) What is considered 'sufficient proof' And this, of course, must be answered in a world where all knowledge of hazards and risk moves in the presuppositions of probability theory.

4) Where hazards and destruction are recognised and acknowledged, who decides issues of liability, compensation and costs for the affected parties, and who rules on appropriate forms of future monitoring and regulation?"

\section{Public Sector Software Partnerships in India}

The partnership between the state and civil society is best illustrated by the relationships between the government of Kerala's IT@School project and the NGO the Society for Promotion of Alternative Computing and Employment (SPACE).

The example of Kerala is well known. To a large extent, the commitment to public sector software there is the result of political will by both major political parties. Kerala is home to a number of passionately committed civil servants and civil society activists to the values of free and open source software solutions. In that context, the relationship between the Government of Kerala and SPACE has been especially significant. Since 2005, SPACE has been involved in supporting extensive, free software-based government projects in the areas of education, local language computing, e-governance, micro-enterprise and in the social sector, inclusive of e-training and support for people with disabilities, hospitals and community libraries.

The FOSS-based IT@School project in Kerala has led to ICT-enabled education in 8000 schools in the state and involved the training of 200 master trainers and 5600 IT coordinators (selected from teaching staff). The publically owned software has been bundled into a single CD for a one-point installation - which would not have been achievable in the context of the use of proprietary software (see Thomas, 2011). The objectives of SPACE are:

- Promote the use of FOSS in the public, private, and governmental sectors as well as for personal/home use; 
- Develop a model for FOSS-based employment generation that is appropriate to Kerala's context, by identifying appropriate business opportunities and providing support services including training and micro-business incubation;

- Carry out research and development activities for the development of essential prototypes that bridge existing gaps in software, so as to enable widespread use of FLOSS;

- Ensure that Kerala is able to develop sufficient numbers of high-quality human resources in the FLOSS domain.

Using the GNOME Desktop, Ubuntu operating system and the assistive technology and screen-reader software ORCA (created by Sun Microsystems), SPACE has pioneered the combinations of speech synthesis technology, Braille, and magnification to create a powerful aural tool for the visually impaired (via a program called Insight) that is complemented with an audio magazine, Swaram. An important aspect of ORCA is that it is free software, since its proprietary counterpart costs about US\$1,300. SPACE works collaboratively with state actors such as the National Informatics Centre and the Centre for the Development of Advanced Computing (C-DAC), quasi-governmental bodies, NGOs and civil society.

These partnerships are significant for several reasons:

- The relationship between the state and civil society has been fraught and most if not all national political parties including the established political 'Left' have periodically had major issues with the NGO sector over matters related to accountability, foreign funding and the national interest.

- National initiatives such as the Right to Information movement, the National Rural Employment Guarantee Act (NREGA), and the Right to Food campaign, that have been significantly moulded by civil society, have touched a chord and have led to a new openness related to civil society involvement in policy making.

- The government's commitment to the knowledge economy and to e-governance has led to explorations of cost-benefits and software standards that allow for nation-wide access and the affordable use of software.

- This commitment has meshed with civil society interests and an appreciation of 'expertise' in civil society that can be harnessed to the development of software standards and public sector software

- Partnerships between the state and civil society have contributed to an understanding of the specificity of public sector software as an essential building block in nationwide development and of the need for Open Source based digital learning material.

\section{Public Software Challenges}

While there are, at any given time, a number of e-governance initiatives in India that are powered by public sector software solutions such as the Linux-based Bharat Operating System Solutions (BOSS), there are inter-state variations in the deployment of such software platforms. While the Southern states, particularly Kerala, and to a lesser extent Tamilnadu and Karnataka, have adopted FOSS-based platforms, along with Gujarat, 
Orissa, West Bengal and Assam, a number of states in North and Central India have yet to follow suit. The Government of Assam's Information technology Policy (2009: 12161217), for example, specifies FOSS as the basis for public sector software.

While the lack of awareness of FOSS-based solutions does exist, a more formidable issue is the pre-existing lock-ins and tie-ups that dominant software players such as Microsoft have with state governments in India. In the state of Maharashtra, for example, the Department of Education and Microsoft have entered into a contract whereby Microsoft will set up IT academies and train teachers at no cost to the state and where even curriculum design will be handled by Microsoft. Trade bodies such as the National Association of Software and Services Companies (NASSCOM) and the Manufacturing Association for Information Technology (MAIT) have also played a role in trying to water down the Draft Policy on Open Standards for e-Governance by lobbying for multiple standards and royalty encumbered standards (see IT for Change). At a workshop held in Bangalore in February 2010 on Software Principles for the Public Sector, a resource paper included examples of software deployment that did not adhere to public sector principles. Among the nine examples presented was the following -a case of software use in the context of the National Rural Employment Guarantee Scheme (NREGA) in Andhra Pradesh. The software used is owned by a software vendor that controls the source code. As a result, the department overseeing the NREGA is dependent on a particular vendor and locked-in to an expensive licensing arrangement, and to agreements that are detrimental to public sector interests. These include the need to share software inter-sectorally and inter-state. Unfortunately, such arrangements are far too typical of the development of e-Governance applications in the country.

This example clearly illustrates the dangers of risk associated with private sector access to public data sets, including documents and databases that cover a wide variety of domain areas. Control over domain specific data can lead to its commercial exploitation and compromise privacy and security, resulting in digital and other divides. It can be argued that the payment of license fees, the lack of access to the source code, the lack of competition and the inability to innovate or reuse software are, from a public perspective, a case of 'organised irresponsibility'.

One of the major issues facing the public sector software movement is the fact that they are involved in both 'reacting' and responding to the reality of multiple standards and issues with interoperability in e-governance projects and the politics of resistance to change at government levels. They are also proactively lobbying for a more focussed, intelligent, centralised approach to public sector software development in India.

The silo approach to departmental management affects the sharing of content, and this is a major concern in India, where consanguineous units act as if they are unrelated. The lack of UNICODE compliant fonts, for example, has led to compatibility issues. UNICODE is a character-encoding scheme that allows characters from the world's major languages to be encoded in a single character set. This is a key issue in the context of e-governance, given that the intent is to deliver e-governance in the language spoken by the common person. This is a challenge in the context of immense language diversity: 500 languages, 216 mother tongues, 10,000 dialects, 22 constitutionally recognised languages. While there are a number of initiatives in India that are looking to deliver on free software Unicode typefaces, much more work needs to be done in this regard. 
The lack of training in FOSS, and the resistance to FOSS in the public sector, are also an issue that public sector software enthusiasts have to contend with.

At the end of the meeting in Bangalore held in February 2010, there were general areas of agreement related to public software (PS):

- Ownership issues of process/source code - PS should be government-owned, and this ownership should be meaningful and well-documented. Involvement of private players is welcome insofar as ownership of source code was not vested with private agencies.

- Technological issues -UNICODE fonts, geographical standards, language standards, etc. need to be developed for free and open use, and mandated by policy

- Wider community should be involved along with domain experts, technology experts to develop and customise PS

- Need shareable data between government departments - availability of all public software on a single platform/portal for use across departments and states

\section{Conclusions}

The emphasis on public sector software by the Indian government illustrates the state's commitment to information futures in India in which the majority of people have access to maximum public data flows in a language of their choice. While there are plans afoot to deliver e-governance via localised 'Common Services Centres', the equivalent of telecentres, it is anybody's guess as to whether or not such centres will facilitate access for all Indians irrespective of caste, gender, class and other markers of identity and status. To belabour a point that I have made in a number of my writings on the media in India (see Thomas 2010), such reforms can only lead to social change if they are complemented by other social reforms.

While disintermediation effects such as bypassing the middleman certainly need to be celebrated, endemic asymmetries can and do lead to a reinvention of power and privilege in the context of network societies. In other words, the politics of access and affordable use also need to be dealt with. However, and despite such concerns and continuing issues with the reputation of the Indian state as a habitual recalcitrant whose interests are at varying odds with millions of its citizenry, public sector software clearly reveals that the Indian state is indeed complex, and multifaceted in its response and commitment to the welfare of its citizenry. Despite its many shortcomings it is also occasionally capable of supporting the project of substantive democracy.

\section{Notes}

1. Pradip Thomas is Co-Director, Centre for Communication and Social Change, University of Queensland. E-mail: pradip.thomas@uq.edu.au

\section{References}

Allen, A. (2009) “Open software 'best for taxpayer"” (8), Supply Management, 14, 5.

Batty, M., Crooks et al (2010) "Data mash-ups and the future of mapping" (1-45), JISC Technology \& Stand- 
ards Watch, September. Available at: http://www.jisc.ac.uk/media/documents/techwatch/jisctsw_10_01. pdf Accessed on September 29, 2010.

Beck, U. (1997) “Global Risk Politics” (18-33) The Political Quarterly, 68, B.

Beck, U. (1999) "Beyond the nation state" (25-27) The New Statesman, December 6.

Bountouri, L., Papatheodorou, C., Soulikias, V., \& Stratis, M. (2009) "Metadata interoperability in public sector information" (204-231), Journal of Information Science, 35, 2.

Chatfield, T. \& Crabtree, J. (2010) "Mash the State" (42-46) Prospect Magazine, 167, February.

Chatterjee, P. (2004) The Politics of the Governed: Reflections on Popular Politics in Most of the World. NY: Columbia University Press.

Cottle, S. (1998) “Ulrich Beck, 'Risk Society’ and the Media: A Catastrophic View?” (5-32), European Journal of Communication, 13, 5 .

Ensuring adoption of progressive national e-governance standards policy, IT for Change. Available at: http:// www.itforchange.net/component/content/article/220-open-standards-campaign.html Accessed on September $28,2010$.

Directive 2003/98/EC of the European Parliament and of the Council of 17 November 2003 on the re-use of public sector information. Available at: http://eur-lex.europa.eu/LexUriServ/LexUriServ.do?uri=OJ:L: 2003:345:0090:0096:EN:PDF. Accessed on April 12, 2011

Draft National Policy on Open Standards for e-Governance (2009). Available at: http://fosscomm.in/Ope nStandards?action=AttachFile\&do=get\&target=Policy_On_Open_Standards_V2.pdf. Accessed on September 28, 2010.

Federspiel, S.B. \& Brincker, B. (2010) "Software as Risk: Introduction of Open Standards in the Danish Public" (38-47), The Information Society, 26, 1.

Ghosh, R.A., Glott, R., Schmitz, P-E., \& Boujraf, A. (2008) OSOR Guidelines Public procurement and Open Source Software (1-117), IDABC Dissemination of Good practice in Using Open Source Software, Unisys Belgium, UNU-MERIT.

Heeks, R. (1998) "Information Age reform of the Public Sector: the Potential and Problems of IT for India" (121), Information Systems for Public Sector Management, Working Paper Series No. 6. October, Institute for Development Policy and Management, University of Manchester. Available at: http://unpan1.un.org/ intradoc/groups/public/documents/NISPAcee/UNPAN015479.pdf. Accessed on September 28, 2010.

Holmstrom, J., \& Robey, D. (2005) "Inscribing organisational change with information technology" (265187) in Czarniawska, B. \& Hernes, T. (eds.) Actor-Network Theory and Organising. Malmö: Liber \& Copenhagen Business School Press.

Indian Labour Market Report (2008) ADECCO Institute, Tata Institute of Sciences. Available at: http://www. esocialsciences.com/data/articles/Document11452009240.3434107.pdf Accessed on September 29, 2010.

Information Technology Policy of Assam (2009), The Assam Gazette, $4^{\text {th }}$ August. Available at: http://assamgovt.nic.in/pdf/ITPOLICY-2009-Final-Gazette-Style.pdf Accessed on September 28, 2010.

Insight. Available at: http://insight.kerala.gov.in/about/ Accessed on May $11^{\text {th }}, 2011$.

Kanungo, V. (2010) Government of India to invest in Rs. 20,000 crores on e-Governance by 2014, e-GovWorld 2010, July 19. Available at: http://67.223.235.55:8081/eGovWorld/newsupdate/opportunities-forindian-it-companies-to-beat-global-demand-in-it-services-as-government-of-india-decides-to-investrs-20-000-crore-on-e-governance-projects-1 Accessed on September 27, 2010

Kelty, C.M. (2005) “Geeks, Social imaginaries and Recursive Publics" (185-214), Cultural Anthropology, $20,2$.

Kelty, C.M. (2008) Two Bits: The Cultural Significance of Free Software. Durham \& London: Duke University Press.

Krishnan, K. (No date) "Localisation and language technology standards" (1-25), ppt., National Informatics Centre (NIC). Available at: http://www.panl10n.net/Presentations/Bhutan/Consultation/NIC\%20India. ppt.pdf Accessed on September 30, 2010

Matoria, R. K., Upadhyay, P. K., \& Moni, M. (2007) “Automation and networking of public libraries in India using the e-Granthalaya software from the National Informatics Centre" (47-58), Electronic Library and Information Systems, 41, 1

Mazdoor Kisan Shakti Sangathan. RTI pioneers. Available at: http://www.mkssindia.org/ Accessed on October 25,2011

Naipaul, V. S.(1998), India: A Million Mutinies Now, Vintage, NY

Public Sector Software Principles. Available at: http://flossinclude.org/south-india-regional-workshop-onsoftware-principles-for-the-public-sector-with-focus-on-public-education-on-1 st-and-2nd-february2010-in-bangalore Accessed on October 25, 2011

Society for Promotion of Alternative Computing and Employment. Available at: http://www.space-kerala.org/ node/10 Accessed on May $11^{\text {th }}, 2011$.

Software Principles for the Public Sector with focus on Public Education, February 1-2, 2010, Bangalore, Workshop Report. 
South India regional Workshop on 'Software Principles for the Public Sector, with Focus on Public Education' Case Studies - Public Software (2010), February.

Thomas, P. N. (2010) Political Economy of Communications in India: The Good, the Bad and the Ugly. New Delhi: Sage.

Thomas, P. N. (2011) Negotiating Communication Rights: Case Studies from India. Los Angeles, London, New Delhi, Singapore, Washington DC: Sage.

What is Public Software, Public Software Centre. Available at: http://public-software-centre.org/node/31 Accessed on September 28, 2010. 